\title{
Dietary intakes of 6-24-month-old urban South Island New Zealand children in relation to biochemical iron status
}

\author{
Patsy Soh ${ }^{1}$, Elaine L Ferguson ${ }^{1, *}$, Joanne E McKenzie ${ }^{2}$, Sheila Skeaff ${ }^{1}$, Winsome Parnell ${ }^{1}$ \\ and Rosalind S Gibson ${ }^{1}$ \\ ${ }^{1}$ Department of Human Nutrition, University of Otago, PO Box 56, Dunedin, New Zealand: ${ }^{2}$ Department of \\ Preventative and Social Medicine, University of Otago, PO Box 56, Dunedin, New Zealand
}

Submitted 20 March 2001: Accepted 15 August 2001

\begin{abstract}
Objective: To investigate food sources and intakes of iron, and dietary factors associated with serum ferritin levels in 6-24-month-old children.

Design: A cross-sectional survey employing proportionate cluster sampling was conducted in 1998/1999. Dietary intakes were assessed using a non-consecutive 3-day weighed food record. Serum ferritin and C-reactive protein were analysed from non-fasting venepuncture blood samples and general sociodemographic data were collected.

Setting: Cities of Christchurch, Dunedin and Invercargill, New Zealand.

Subjects: Randomly selected healthy 6-24-month-old non-breast-feeding children $(n=226)$.

Results: Total iron intakes ( \pm standard deviation (SD)) among non-breast-feeding infants ( $<12$ months old; $n=42)$ and toddlers ( $\geq 12$ months old; $n=184$ ) were $8.4 \pm 2.9 \mathrm{mg} \mathrm{day}^{-1}$ and $5.0 \pm 2.5 \mathrm{mg} \mathrm{day}^{-1}$, respectively. Fifteen per cent of infants and $66 \%$ of toddlers were at risk of inadequate iron intakes. Main sources of dietary iron were infant formula (60\%) for infants and cereals (31\%) for toddlers. Meat contributed on average $2 \%$ and $10 \%$ of dietary iron in the infant and toddler diets, respectively. Dietary factors positively associated with serum ferritin were intakes of iron and vitamin $\mathrm{C}$, whereas intakes of calcium and dietary fibre were negatively associated. For each $1 \%$ increase in percentage of energy from iron-fortified formula concomitant with a $1 \%$ decrease from dairy products, there was a $4.2 \%$ increased odds of replete iron stores (ferritin $\geq 20 \mu \mathrm{gl}^{-1}$ ).

Conclusions: Toddlers were at higher risk of sub-optimal iron intakes than infants. Results suggest that a diet high in bioavailable iron is important for optimising the iron stores of young children in New Zealand.
\end{abstract}

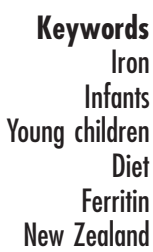

Sub-optimal iron status often occurs during the first two years of life as young children change from a predominantly milk-based diet to one based on solid foods. During this time, iron requirements for growth are high and foetal iron stores are depleted ${ }^{1}$. After about six months of age, full-term infants can no longer meet their requirements from breast milk or unfortified cows' milk alone because of the low iron content of milk ${ }^{1}$. As a result, sources of iron from non-milk foods and iron-fortified products play an important role in maintaining optimal iron status ${ }^{1}$.

When selecting complementary foods, the amount of iron, its form (haem or non-haem), and intakes of enhancers and inhibitors of dietary iron absorption are important considerations. Intakes of meat, a highly bioavailable source of haem iron, tend to be low in weanlings ${ }^{2}$. On the other hand, the intake of iron from iron-fortified products can be relatively high, especially in countries where the consumption of iron-fortified infant cereals and formulas is promoted ${ }^{1}$.

In modern industrialised countries, there is a wide range of complementary foods available for feeding infants and young children. As their selection is influenced by a variety of factors, including local health promotion activities, it is imperative to understand the role of diet in optimising the iron status of young children in a particular environment. This will assist in the formulation of specific public health recommendations with regard to iron for that environment.

To date, the major food sources of iron and the relationship between biochemical iron status and the dietary intakes of young children in industrialised countries have not been extensively investigated in representative community-based groups ${ }^{3-9}$. This is surprising given the importance of ensuring adequate iron 
status in infancy and childhood for optimal health, growth and cognitive development ${ }^{1}$. Therefore, the objectives of this study were to assess intakes, major food sources and modifiers of dietary iron absorption, and their association with serum ferritin concentrations in a randomly selected sample of healthy 6-24-month-old urban South Island New Zealand (NZ) children. These results come from a more comprehensive survey designed to investigate the dietary and/or biochemical iron, zinc and iodine status of these children.

\section{Methods}

\section{Survey design}

A community-based, cross-sectional survey of 6-24month-old infants and children $(n=323)$ was conducted in three cities in the South Island of NZ between May 1998 and March 1999. A non-fasting venepuncture blood sample, non-consecutive 3-day weighed food records and a pre-tested general questionnaire (self-administered) were collected during two home visits. Ethical approval was obtained from the Ethics Committee of the University of Otago, Dunedin, NZ. Written informed consent was obtained from a primary caregiver for each child participating in the survey.

\section{Participant recruitment}

Children were randomly selected using proportionate cluster sampling, whereby the number of children recruited in each city was in proportion to the population in each city (i.e. 217 in Christchurch, 66 in Dunedin and 40 in Invercargill). The sample size was selected to estimate the prevalence $( \pm 10 \%)$ of sub-optimal iron status of $6-$ 24-month-old urban South Island NZ children, assuming a design effect of 2 , a prevalence rate $\leq 20 \%$ and an $18 \%$ rate of attrition. To recruit these children, address start points were randomly selected from Census Unit Areas (CUAs) in each city after weighting each CUA according to the number of households per area. In each city, start points were visited in the order of selection until the required number of children were recruited into the study (i.e. 104 start points in Christchurch, 31 in Dunedin and 12 in Invercargill). At each start point, 80 households were visited following a pre-determined direction to identify all eligible children. Each start point was visited three times at different times of the day and on different days of the week to minimise the selection bias introduced when adults were not at home (occurred in 13\% of the households). Children were eligible to participate if they were 6 to 24 months of age inclusive and apparently healthy. Despite these criteria, two children were outside this age range (i.e. 5.8 and 26.9 months). If more than one child was eligible per household, then one was randomly selected to participate in the study. Of the eligible 532 children identified, 323 agreed to participate, providing a total overall response rate of $61 \%$. Proportional numbers of children were recruited per month from each city from May until December 1998. Only children from Christchurch were recruited in February/March 1999 (i.e. 28 children).

\section{Dietary assessment}

A 3-day weighed diet record was collected from each child using dietary scales accurate to within $\pm 1 \mathrm{~g}$ (model Salter Electronic, Salter Housewares Ltd, UK). Dietary intakes were recorded on randomly selected non-consecutive days, including two weekdays and one weekend day, within a 3-week period. An attempt was made to represent each weekday/weekend day an equal number of times across the population, as well as different days of the week an equal number of times on the first, second and third recording days. No attempt was made to adjust for the disproportionately higher number of weekend to weekdays, because the effect was probably minimal based on a recent study of older pre-school NZ children ${ }^{10}$. A parent of each child was given detailed written and oral instructions on how to collect the diet records, and received a schedule specifying the pre-assigned days for diet recording. A reminder telephone call was made to the parents the day before and another on the first day of dietary data recording for encouragement and to answer any questions. At the end of each diet record day, caregivers recorded the child's health status and whether or not their child had taken a supplement containing iron on that day. Details of the type, form and amount of iron supplement consumed were also noted. If the child was ill, the effect on appetite was recorded. All diet records were checked and clarified with the caregiver by a research assistant within a few days of completion of the 3-day weighed record.

Diet records were analysed using the software program Diet Cruncher $1997^{11}$, which calculated the average daily intakes of energy, nutrients and major food sources of iron for each individual using the NZ Food Composition Database $^{12}$. All diet record data entries were rechecked by one person to minimise errors and ensure consistency in data-entry decisions. If a child had taken a dietary supplement that contained iron on the recording day, the extra iron was added to the amount of iron from the diet. Haem iron intakes were estimated by assuming that $40 \%$ of the iron from meat, poultry, fish and shellfish eaten was haem iron $^{13}$. Breast-feeding children $(n=75)$ were excluded from the diet analysis because breast milk consumption was not quantified. Data from children consuming less food than usual, due to illness, were also excluded ( six had two days' intake and 47 had one day's intake excluded). Five children were excluded who were sick on all three diet-recording days and diet records were not able to be collected from 17 children. In total 226 diet records were, therefore, analysed.

The percentage of children estimated to be at risk of inadequate dietary iron intake was calculated by using a 
short cut of the probability analysis approach ${ }^{14}$. This involves calculating the proportion of children with usual iron intakes below the UK Estimated Average Requirement (EAR) for iron $^{15}$ after adjusting the observed intake distributions to approximate the 'usual' intake distribution for the population using the program C-SIDE ${ }^{16}$. The EAR was chosen because it provides a more realistic estimate of the percentage at risk for low intakes than the recommended dietary intakes (RNI) on a population basis $^{14}$. The intake distributions were adjusted because three days of dietary intake does not provide an estimate of 'usual' intakes for the individual. An unadjusted intake distribution would result in an overestimation of the proportion at risk in this instance.

\section{Biochemical assessment}

Where feasible, a non-fasting venepuncture blood sample was collected from each child into trace-element-free evacuated containers (Becton Dickinson, Franklin Lakes, NJ) $(n=263)$, processed within $4 \mathrm{~h}$ and the separated serum stored at $-80^{\circ} \mathrm{C}$ until analysis. The reasons for not collecting a blood sample were refusal by the primary caregiver $(n=39)$, lack of success in collecting the sample $(n=22)$ and insufficient sample for all biochemical tests $(n=9)$. There were no significant differences in dietary intakes comparing those with $(n=213)$ and without $(n=$ 31) a blood sample among children who were not currently breast-feeding after controlling for age and gender. This suggests that selection bias was not introduced via attrition. Serum ferritin was analysed by enzyme-linked immunosorbent assay (ELISA) using a commercial kit (Ramco Laboratories, Inc., Houston, TX). Serum C-reactive protein (CRP) was also measured, as an index of infection, using a Behring Turbitimer System (Behringwerke AG, Marburg, Germany). Values $\geq 10 \mathrm{mg} \mathrm{l}^{-1}$ were considered to be indicative of infection $^{17}$. The accuracy and precision of analytical techniques for serum ferritin were ensured by analysing an international reference material (i.e. NIBSC 3rd International Ferritin Standard), an in-house pooled serum sample, and a high, medium and low commercial control (catalogue number S-22, Ramco Laboratories Inc., Houston, TX). The results for the NIBSC reference material showed an average of $59.2 \pm 4.1 \mathrm{ng} \mathrm{ml}^{-1}$ compared with a certified concentration of $63.0 \mathrm{ng} \mathrm{ml}^{-1}$. The analysed high, medium and low Ramco controls were 293.1 \pm 15.6 , $68.0 \pm 4.3$ and $12.4 \pm 0.9 \mathrm{ng} \mathrm{ml}^{-1}$ compared with certified concentrations of $280.0 \pm 62.0,68.8 \pm 16.1$ and $12.1 \pm$ $4.8 \mathrm{ng} \mathrm{ml}^{-1}$, respectively. The coefficient of variation for the serum ferritin analysis was $6.8 \%$.

\section{Statistical analysis}

All statistical analyses were performed using Stata version 5.0 (Stata Corporation, College Station, TX). Serum ferritin and dietary intakes of iron and vitamin $\mathrm{C}$ were log-transformed to normalise the distributions for some analyses.
Multiple linear regression was performed on the macronutrients (energy, carbohydrate, protein, fat) and selected micronutrients (log iron, zinc, dietary fibre, log vitamin C) to evaluate whether there were differences in intakes by age, gender and ethnicity.

It was also used to investigate the effect of dietary factors on serum ferritin after adjusting for potential confounding factors and sampling design (city and CUA) using the SURVEY command. Dietary factors chosen were those already known to influence iron status, and included intakes of iron, vitamin C, calcium and dietary fibre. The non-dietary factors included recent infection (CRP $<10 \mathrm{mgl}^{-1}$ and $\geq 10 \mathrm{mgl}^{-1}$ ), ethnicity (Caucasian, nonCaucasian), age group (6-11.9 months and 12-24 months) and prematurity. The latter were chosen to control for the confounding of infection on serum ferritin levels ${ }^{17}$, potential ethnic group differences in health status $^{18}$, and differences in iron requirements across age groups and between premature and full-term infants. Model assumptions were investigated using various residual plots. Variance inflation factors (VIFs) were used to check for the presence of multicollinearity. There was no evidence of multicollinearity as all VIFs were less than 10 and the mean of all VIFs was 1.16.

Inter-group differences in the percentage of energy from food groups were assessed using the Mann-Whitney $U$-test. Groups were defined as: (1) those with dietary iron intakes below and equal to or greater than the UK RNI ${ }^{15}$ for iron (i.e. $7.8 \mathrm{mg} \mathrm{day}^{-1}$ for infants and $7.0 \mathrm{mg} \mathrm{day}^{-1}$ for toddlers); and (2) children with serum ferritin concentrations below and $\geq 20 \mu \mathrm{gl}^{-1}$ (i.e. replete iron stores) ${ }^{19}$. Good instead of poor iron stores were selected because iron intervention programmes aim to attain optimal iron status. For sociodemographic differences between currently breast-fed and non-breast-fed children, the proportions were analysed via Chi-square analysis.

The effect of increasing intakes of iron-fortified formula while concomitantly decreasing dairy product intakes on the odds of attaining replete iron stores was further explored using multiple logistic regression analysis. In this analysis, food groups were entered as the percentage of energy from a food group to control for varying levels of energy intake ${ }^{20}$; and age group (infant and toddler) was also included to control for age differences in serum ferritin levels. The six food groups selected were iron-fortified infant formula, meat, poultry and fish (MPF), cereals, fruit and vegetables, dairy products and miscellaneous. As the sum of percentage energy from each food group is 100\%, it was necessary to exclude one food group from the model. Dairy products were excluded, which means that for each $1 \%$ increase in energy from a particular food group in the model, there would be a concomitant $1 \%$ decrease in energy from dairy products to maintain the sum of $100 \%$. Regression diagnostic plots were examined for influential covariate patterns. 


\section{Results}

Selected sociodemographic and iron status characteristics of the survey participants showed that children who were currently breast-feeding were younger, less likely to be Caucasian, and had a higher percentage of mothers with a tertiary level of education than those who were not currently breast-feeding (Table 1). The percentage of children with low serum ferritin levels ranged from 11 to $16 \%$ depending on their breast-feeding status (Table 1). Breast-feeding had been initiated for $87 \%$ of the children, with $68 \%$ and $57 \%$ still being breast fed at 4 and 6 months of age, respectively.

Significant age group differences in median daily intakes of energy, protein, dietary fibre, total iron, haem iron, non-haem iron and calcium, and significant gender differences for energy intakes, were observed among the non-breast-feeding children (Table 2). In contrast to other dietary intakes, the intakes of iron (per day and per $\mathrm{kg}$ body weight) and the iron density of the diets were significantly higher for infants $(<12$ months old $)$ than for toddlers. There were no significant differences across seasons (autumn/winter and spring/summer) in any of the dietary intakes. After adjusting the dietary intake distribution using C-SIDE, $66 \%$ of toddlers compared with only $15 \%$ of infants were at risk of low dietary iron intakes.
The major food sources of dietary iron were ironfortified infant formulas (59.4\%), commercial infant foods (8.2\%), fruit/vegetables (7.4\%) and MPF (2.4\%) for infants $(n=42)$; and cereals $(30.9 \%)$, fruit/vegetables (15.1\%) and MPF (10.4\%) for toddlers $(n=184)$ (Fig. 1$)$. As only $16 \%(n=30)$ of toddlers consumed iron-fortified infant formula, no dietary iron was contributed by this food group on average in this age group.

Dietary factors positively associated with serum ferritin levels, after controlling for possible confounders, were intakes of total iron (diet+supplemental iron) and vitamin $\mathrm{C}$, whereas intakes of calcium and dietary fibre intakes were negatively associated (Table 3).

On average, the energy contribution from ironfortified foods was significantly higher and dairy products significantly lower in diets that achieved the UK RNI ${ }^{15}$ for iron and in children with good iron stores (i.e. $\geq 20 \mu \mathrm{gl}^{-1}$ ) compared with their counterparts (Table 4). Iron-rich diets were also associated with a significantly lower proportion of energy from cereals (Table 4). In contrast, there were no significant differences in the percentage of energy provided by MPF in diets below and equal to or greater than the UK $\mathrm{RNI}^{15}$ for iron and in children with ferritin levels below and $\geq 20 \mu \mathrm{gl}^{-1}$ in either age group.

Logistic regression analysis showed that the odds of replete iron stores increased by $4.2 \%$ with each $1 \%$

Table 1 Selected sociodemographic characteristics by current breast-feeding status

\begin{tabular}{|c|c|c|c|}
\hline & $\begin{array}{l}\text { Currently } \\
\text { breast-feeding } \\
(n=79) \\
n(\%)\end{array}$ & $\begin{array}{l}\text { Not currently } \\
\text { breast-feeding } \\
\quad(n=244) \\
n(\%)\end{array}$ & $\begin{array}{c}\text { All children } \\
(n=323) \\
n(\%)\end{array}$ \\
\hline \multicolumn{4}{|l|}{ Gender } \\
\hline Males & $41(52)$ & $142(58)$ & $183(56)$ \\
\hline \multicolumn{4}{|l|}{ Age(months) $)^{*}$} \\
\hline$<12$ & $54(68)$ & $47(19)$ & $101(31)$ \\
\hline $12.0-17.9$ & $18(23)$ & $86(35)$ & 104 (32) \\
\hline$\geq 18$ & $7(9)$ & $111(46)$ & $118(37)$ \\
\hline \multicolumn{4}{|l|}{ Ethnicity* } \\
\hline Caucasian & $61(77)$ & $210(86)$ & $271(84)$ \\
\hline \multicolumn{4}{|l|}{ Household income (NZ\$)† } \\
\hline $1-20000$ & $12(15)$ & $30(12)$ & $62(19)$ \\
\hline $20001-50000$ & $34(43)$ & $119(49)$ & $135(42)$ \\
\hline 50001 and above & $25(32)$ & $62(26)$ & $87(27)$ \\
\hline \multicolumn{4}{|l|}{ Maternal education $\dagger$} \\
\hline University & $22(28)$ & $44(18)$ & $66(20)$ \\
\hline Diploma & $20(25)$ & $58(24)$ & $78(24)$ \\
\hline Secondary school & $36(46)$ & $132(54)$ & $168(52)$ \\
\hline \multicolumn{4}{|l|}{ Feeding practice* } \\
\hline Breast-fed only & $47(60)$ & $30(12)$ & $77(24)$ \\
\hline Formula-fed only $\ddagger$ & $0(0)$ & $52(21)$ & $52(17)$ \\
\hline Breast- and formula-fed & $32(41)$ & $161(66)$ & $193(60)$ \\
\hline \multicolumn{4}{|l|}{ Prematurity } \\
\hline Yes & $13(16)$ & $35(14)$ & $48(15)$ \\
\hline \multicolumn{4}{|l|}{ Low serum ferritin ${ }^{\S}$} \\
\hline$<10 \mu \mathrm{gl}^{-1}$ & $6(11)$ & $31(16)$ & $37(15)$ \\
\hline
\end{tabular}


Table 2 Median (quartiles) dietary intakes per day and iron intakes per $\mathrm{mJ}$ and per kg body weight by age group and gender for children who are not currently breast-feeding

\begin{tabular}{|c|c|c|c|c|}
\hline & \multicolumn{2}{|c|}{ Infants } & \multicolumn{2}{|c|}{ Toddlers } \\
\hline & Boys $(n=28)$ & Girls $(n=14)$ & Boys $(n=106)$ & Girls $(n=78)$ \\
\hline Energy $(\mathrm{kJ})^{\star} \dagger$ & $3294(2908,3628)$ & $3133(2915,3619)$ & $4143(3654,4679)$ & $3956(3380,4386)$ \\
\hline Protein $(g)^{*}$ & $26(22,32)$ & $23(21,26)$ & $38(30,43)$ & $34(29,38)$ \\
\hline Total iron $(\mathrm{mg})^{\star} \ddagger$ & $8.3(6.8,11.5)$ & $8.6(5.7,9.5)$ & $4.4(3.3,5.3)$ & $4.8(3.4,6.6)$ \\
\hline Haem iron $(\mathrm{mg})^{*}$ & $0.08(0.02,0.20)$ & $0.00(0.00,0.11)$ & $0.19(0.04,0.31)$ & $0.18(0.08,0.27)$ \\
\hline Non-haem iron $(\mathrm{mg})^{\star} \ddagger$ & $7.4(6.2,10.5)$ & $8.8(5.2,9.9)$ & $3.6(2.9,4.7)$ & $3.9(2.8,5.8)$ \\
\hline Iron density $\left(\mathrm{mg} \mathrm{MJ}^{-1}\right)^{\star} \ddagger$ & $2.7(2.1,3.2)$ & $2.4(2.0,3.0)$ & $1.0(0.8,1.3)$ & $1.2(0.8,1.6)$ \\
\hline Iron per $\mathrm{kg}$ body weight $\left(\mathrm{mg} \mathrm{kg}^{-1}\right)^{\star} \ddagger$ & $0.9(0.7,1.2)$ & $0.9(0.7,1.2)$ & $0.4(0.3,0.5)$ & $0.4(0.3,0.6)$ \\
\hline Dietary fibre $(\mathrm{g})^{*}$ & $6(4,9)$ & $6(5,8)$ & $8(6,10)$ & $7(5,9)$ \\
\hline Calcium $(\mathrm{mg})^{\star}$ & $619(492,793)$ & $642(567,720)$ & $687(544,883)$ & $644(509,855)$ \\
\hline Vitamin C (mg) & $62(54,71)$ & $63(60,75)$ & $59(35,85)$ & $58(37,98)$ \\
\hline
\end{tabular}

* Significant difference between age groups (multiple regression analysis, $P<0.05$ ).

†Significant difference between genders (multiple regression analysis, $P<0.05$ ).

$\ddagger$ Dietary iron+supplemental iron.

increase in the percentage energy from iron-fortified formula concomitant with a $1 \%$ decrease from dairy products, after controlling for the percentage of energy provided by other food groups (Table 5).

\section{Discussion}

This study is the first to evaluate dietary intakes and food sources of iron in relation to body iron stores in a representative sample of young, non-breast-feeding NZ children. The results showed that the intakes and/or density of iron in the diets of NZ children were similar to those of young children in the United Kingdom, France, Denmark and Norway, but were lower than those found in North America and Sweden ${ }^{2-7,9,21-25}$, presumably reflecting inter-country differences in the consumption of iron- fortified foods. In our study, $66 \%$ of the toddlers compared with only $15 \%$ of the infants were at risk of low dietary iron intakes, a trend attributable to marked differences in dietary patterns. On average, 60\% of iron and $51 \%$ of energy were obtained from iron-fortified formula in the infant diets compared with $0 \%$ in the toddler diets. In the toddler diets, cereals (31\%) and dairy products (33\%) were instead the main sources of iron and energy, respectively. Such age-related differences in dietary patterns and declines in dietary iron intakes are not unique to $\mathrm{NZ}^{9,21,24,25}$.

Our results showed that dietary iron and iron absorption modifiers were associated with levels of iron stores in these young NZ children. The positive associations found between serum ferritin and intakes of iron and vitamin $\mathrm{C}$, and the negative associations with intakes of calcium and

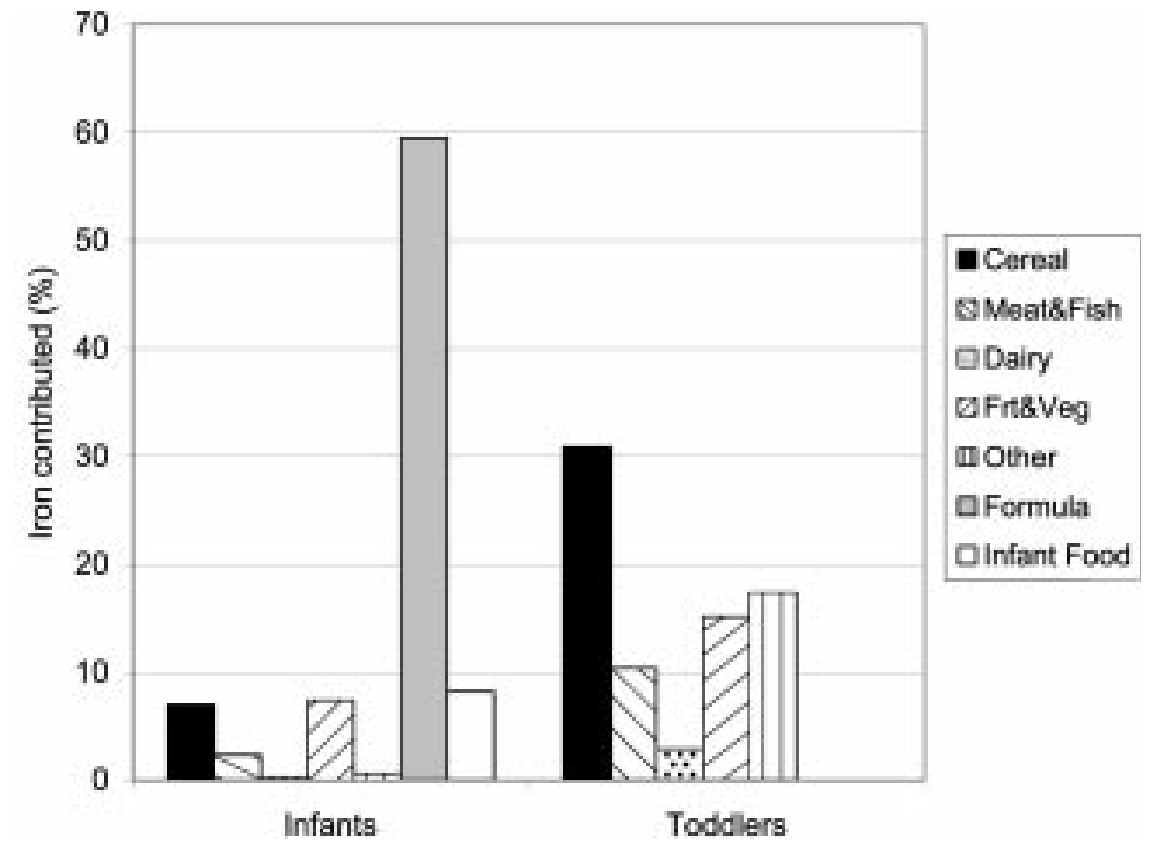

Fig. 1 The percentage of iron contributed by major food groups in the diets of infants ( $<12$ months of age) and toddlers (12-24 months of age) 
Table 3 Dietary factors associated with serum ferritin levels after adjusting for potential confounding factors and survey design $\left(r^{2}=0.30 ; n=179, \mathrm{DF}=8 ; F-\right.$ ratio $\left.=9.97 ; P=0.0000\right)$

\begin{tabular}{lccr}
\hline & $\beta$-value $(95 \% \mathrm{Cl})^{*}$ & Rate ratio & $P$-value \\
\hline C-reactive protein & $0.33(0.20$ to 0.46$)$ & $2.138(1.58$ to 2.88$)$ & 0.000 \\
Ethnic group & $0.10(-0.03$ to 0.23$)$ & $1.259(0.93$ to 1.70$)$ & 0.120 \\
Age group (6-11.9 months) & $0.02(-0.07$ to 0.11$)$ & $1.047(0.85$ to 1.29$)$ & 0.680 \\
Premature & $-0.09(-0.20$ to 0.01$)$ & $0.813(0.63$ to 1.02$)$ & 0.087 \\
Total iron & $0.02(0.01$ to 0.04$)$ & $1.047(1.02$ to 1.10$)$ & 0.008 \\
Calcium & $-0.0002(-0.003$ to -0.00008$)$ & $0.9995(0.993$ to 0.999$)$ & 0.002 \\
Dietary fibre & $-0.01(-0.02$ to -0.004$)$ & $0.977(0.95$ to 0.99$)$ & 0.006 \\
Vitamin C & $0.001(0.0003$ to 0.002$)$ & $1.002(1.001$ to 1.01$)$ & 0.043 \\
\hline
\end{tabular}

${ }^{*} 95 \%$ confidence interval.

dietary fibre, are consistent with the known impact of these dietary factors on iron absorption ${ }^{26,27}$. They also concur with suggestions that the level of enhancers and inhibitors of iron absorption can be just as important as the amount of dietary iron because of their effect on bioavailability ${ }^{28}$.

Not all studies have reported a positive association between dietary iron intakes and biochemical iron stores in weanlings ${ }^{4,7,8,29}$. This lack of consistency is not surprising, because the effect of potential confounding factors was not always taken into account, and in some cases only single 24-hour recalls were used to estimate iron intakes ${ }^{8}$. Based on our data, the biological impact of the enhancers and inhibitors in the diets of these young NZ children was not profound. For example, each unit increase in intake of iron, vitamin $\mathrm{C}$, calcium and dietary fibre was only associated with a $+4.7 \%,+0.2 \%,-0.05 \%$ and $-2.3 \%$ change in serum ferritin levels, respectively. However, our results probably underestimated the true impact of diet because associations between dietary and biochemical indices are notoriously difficult to demonstrate, particularly in this age group given their rapid changes in food consumption patterns and the errors associated with the collection of dietary data. Moreover, three days of dietary intake do not provide a precise estimate of 'usual' intake for an individual child ${ }^{10}$, resulting in an attenuation of associations.

The lack of association between iron stores and the percentage of energy contributed by MPF in our study (Tables 4 and 5) was unexpected and contrary to findings reported by others ${ }^{5,7,29-31}$. Haem iron is more bioavailable than non-haem iron and has been shown to increase the absorption of iron from $10 \%$ to $15 \%$ in a vegetable meal with added meat in a recent short-term iron bioavailability study in infants ${ }^{32}$. Perhaps the lack of association between MPF intakes and iron stores, in our study, was related to the low intake of haem iron and small proportion of energy contributed by MPF in the diets of these NZ children compared with children elsewhere (i.e. 0.16 vs. $0.28-$ $0.46 \mathrm{mg} \mathrm{day}^{-1}$ and $\leq 10 \%$ in NZ vs. $\left.16-29 \%\right)^{3,4,7,9,29,33}$. Consequently, our results do not disprove the benefits of increasing meat consumption to enhance iron stores in 624-month-old NZ children. Instead they emphasise that intakes of meat, poultry or fish are low, and that NZ primary caregivers need to encourage toddlers to consume more of these flesh foods by preparing them in ways that are palatable for young children.

Dietary strategies for increasing intakes of iron and its absorption include the promotion of intakes of animal products, fruits/vegetables (vitamin C) and/or ironfortified foods ${ }^{34}$. Results from our study indicate that encouraging the consumption of iron-fortified foods into the second year of life could be beneficial (Tables 4 and 5). Such results were not surprising, because of the substantially higher iron content of iron-fortified formula

Table 4 Median (quartiles) percentage of energy from selected food groups in diets above and below the UK RNI* for iron and in children with serum ferritin concentration above and below $20 \mu \mathrm{gl}^{-1}$ by age group

\begin{tabular}{|c|c|c|c|c|c|c|}
\hline & & $\begin{array}{l}\text { Infant } \\
\text { formula }\end{array}$ & Dairy products & $\begin{array}{c}\text { Animal } \\
\text { products }\end{array}$ & Cereals & Fruit and vegetables \\
\hline & Diet & & & & & \\
\hline \multirow[t]{2}{*}{ Infants } & $<\mathrm{RNI}^{*}(n=20)$ & $44(28,58)$ & $10(2,17)$ & $3(0,5)$ & $14(10,21)$ & $10(18,19)$ \\
\hline & $\geq \mathrm{RNI}(n=22)$ & $59+(48,80)$ & $1+(0,10)$ & $1(0,4)$ & $7 \dagger(1,18)$ & $8 \dagger(3,11)$ \\
\hline \multirow[t]{3}{*}{ Toddlers } & $<\mathrm{RNI}(n=162)$ & $0(0,0)$ & $34(26,45)$ & $5(2,10)$ & $23(16,30)$ & $10(7,15)$ \\
\hline & $\geq \mathrm{RNI}(n=26)$ & $17 \dagger(0,45)$ & $14 †(3,24)$ & $4(0,7)$ & $16+(11,22)$ & $10(7,17)$ \\
\hline & Ferritin & & & & & \\
\hline \multirow[t]{2}{*}{ Infants } & $<20 \mu \mathrm{gl}^{-1}(n=14)$ & $47(35,62)$ & $11(0,22)$ & $3(0,5)$ & $15(6,22)$ & $11(7,20)$ \\
\hline & $\geq 20 \mu \mathrm{gl}^{-1}(n=20)$ & $55(41,74)$ & $4(0,12)$ & $1(0,3)$ & $10(2,20)$ & $8 \dagger(3,12)$ \\
\hline \multirow[t]{2}{*}{ Toddlers } & $<20 \mu \mathrm{gl}^{-1}(n=96)$ & $0(0,0)$ & $36(28,45)$ & $5(2,10)$ & $10(15,28)$ & $9(6,15)$ \\
\hline & $\geq 20 \mu \mathrm{gl}^{-1}(n=57)$ & $0 †(0,1)$ & $26 †(19,37)$ & $4(2,7)$ & $9(15,30)$ & $11(7,18)$ \\
\hline
\end{tabular}

${ }^{*}$ Reference Nutrient Intake $(\mathrm{RNI})^{15}=7.8 \mathrm{mg} \mathrm{day}^{-1}$ for infants and $7.0 \mathrm{mg} \mathrm{day}^{-1}$ for toddlers.

† Significant difference between children with high and low iron diets and between children with different serum ferritin concentrations for each age group (Mann-Whitney U-test; $P<0.05$ ). 
Table 5 Dietary patterns ${ }^{*}$ associated with good iron stores (serum ferritin $\geq 20 \mu \mathrm{gl}^{-1}$ ) in non-breast-feeding children ( $n=187$; logistic regression model $\dagger)$

\begin{tabular}{lccc}
\hline Food group & Odds ratio & $95 \%$ Cl & $P$-value \\
\hline Infant formula & 1.042 & 1.014 to 1.070 & 0.004 \\
Animal products & 1.014 & 0.943 to 1.090 & 0.70 \\
Cereals & 1.033 & 1.000 to 1.067 & 0.05 \\
Fruit and vegetables & 1.035 & 0.982 to 1.090 & 0.19 \\
Miscellaneous & 1.036 & 1.004 to 1.069 & 0.03 \\
Age group $^{\S}$ & 1.290 & 0.364 to 4.571 & 0.69 \\
\hline
\end{tabular}

* Percentage of energy from selected food groups.

†Percentage of energy from dairy products was the reference variable (i.e. excluded).

$\neq 95 \%$ confidence interval.

$\S$ Infants $(<12$ months old $)=0$; toddlers $(\geq 12$ months old $)=1$.

compared with dairy products such as cows' milk (i.e. 7$12 \mathrm{mg} \mathrm{l}^{-1}$ for iron-fortified formula in NZ vs. $0.5 \mathrm{mg} \mathrm{l}^{-1}$ for cows' milk $)^{12}$. They are also consistent with a recent longitudinal European study that found that the duration of iron-fortified formula and cows' milk consumption was positively and negatively associated with the iron status of children at 12 months of age, respectively. The duration of meat and fruit/vegetables consumption showed no association with iron status in this study ${ }^{35}$.

In our study, close to $20 \%$ of toddlers and less than $8 \%$ of infants had low iron stores (ferritin $<10 \mu \mathrm{gl}^{-1}$ ) - an agerelated decline that is not unique to $\mathrm{NZ}^{36}$. Our biochemical and dietary results, therefore, raise the question of whether the use of iron-fortified formula should be encouraged up to 24 months of age in an effort to optimise body iron stores. Intervention trials designed to assess the efficacy of consumption of iron-fortified foods by toddlers are limited. In younger children, such trials have shown that consumption of iron-fortified formula enhances iron status, and has no adverse effects on growth or health, compared with the consumption of unfortified formula ${ }^{37-41}$. Also, there are no known advantages of depleted body iron stores in childhood ${ }^{42}$. Nevertheless, concerns have been raised about the potential pro-oxidant effects of excessive unabsorbed ferrous sulphate on the infant gut, and the effects of high dietary iron intakes on the absorption of other trace minerals, especially copper, zinc and manganese ${ }^{43,44}$. Recommending extended use of iron-fortified formula could also have negative economic implications for NZ families because, compared with cows' milk, infant formula is more expensive. Caution is advised, therefore, before making recommendations that would potentially lead to a dramatic reduction in dairy product consumption among toddlers. Particularly when they are only based on descriptive study results such as ours, and moderate (as opposed to excessive) intake of dairy products has never been shown to have a detrimental impact on the iron status in children over 12 months of age. There is clearly a need for more research to assess the efficacy of alternative dietary strategies for increasing the iron stores of NZ toddlers.

Finally, the low response rate in the current study must be noted. More survey participants were Caucasian (84\% vs. 78\%) and had mothers with a university education (20\% vs. 9\%) than were expected based on the 1996 Census data for Christchurch, Invercargill and Dunedin ${ }^{45}$. Nevertheless, intakes and food sources of dietary iron were similar across these groups of children, with the exception of the percentage of iron contributed by fruit, which was significantly higher in diets of children with highly educated mothers compared with others. Hence, results presented in Table 3 and Fig. 1 are probably generalisable to non-breast-feeding, urban, 6-24-monthold South Island NZ children, as long as participants did not differ markedly from non-participants in other ways. Likewise, the differential selection bias across age groups created by excluding breast-feeding children was unlikely to be a strong confounder, when investigating factors associated with variation in serum ferritin levels. Even though $56 \%$ of infants $<12$ months were breast-feeding compared with only $10 \%$ in older children, median serum ferritin levels of currently breast-feeding and non-breastfeeding infants were similar (i.e. 22 vs. $25 \mu \mathrm{gl}^{-1}$ ), and age group was controlled in all statistical analyses.

In summary, our results suggest that the iron intakes of a high proportion of 6-24-month-old non-breast-feeding children were low, particularly among the 12-24-monthold age group. This was attributed to the small proportion of iron provided by iron-fortified foods in the toddlers' diets. Positive associations between intakes of iron and vitamin $\mathrm{C}$, and negative associations with intakes of calcium and dietary fibre, indicate the importance of providing an iron-dense diet rich in enhancers of iron bioavailability for young NZ children - a group with marginal iron status ${ }^{8}$. Dietary strategies worthy of further investigation include the use of iron-fortified infant foods into the second year of life, and perhaps encouraging the consumption of pureed meat from 6 months of age.

\section{Acknowledgements}

This research was supported by a grant from the Health Research Council of New Zealand. We would also like to thank all mothers and children who participated in this survey, Steven Tiszavari for his laboratory expertise and the dedicated research assistants, particularly Wendy Aitken, Jenny Walker and Julie Carter.

\section{References}

1 Booth IW, Aukett M. Iron deficiency anaemia in infancy and early childhood. Arch. Dis. Child. 1997; 76: 549-54.

2 Skinner JD, Carruth BR, Houck KS, Coletta F, Cotter R, Ott D, McLeod M. Longitudinal study of nutrient and food intakes of infants aged 2 to 24 months. J. Am. Diet. Assoc. 1997; 97: 496-504.

3 Gregory JR, Collins DJ, Davies PSW. National Diet and Nutrition Survey: Children aged 1.5-4.5 years. Vol. 1. London: HMSO, 1995.

4 Hercberg S, Papoz L, Galan P, Guery MF, Farnier MA, 
Rossignol C. Iron status and dietary pattern in young children. Nutr. Rep. Intern. 1987; 35: 307-15.

5 Michaelsen KF, Milman N, Samuelson G. A longitudinal study of iron status in healthy Danish infants: effects of early iron status, growth velocity and dietary factors. Acta Paediatr. 1995; 84: 1035-44.

6 Perrson LÅ, Johansson E, Samuelson G. Dietary intake of weaned infants in a Swedish community. Hum. Nutr. Appl. Nutr. 1984; 38: 247-54.

7 Preziosi P, Hercberg S, Galan P, Devanlay M, Cherouvier F, Dupin H. Iron status of a healthy French population: factors determining biochemical markers. Ann. Nutr. Metab. 1994; 38: 192-202.

8 Wham C. Dietary iron intake and iron status of young children. Asia Pacific J. Clin. Nutr. 1996; 5: 196-200.

9 Yeung DL, Pennell MD, Leung M, Hall J, Anderson GH. Iron intake of infants: the importance of infant cereals. Cdn. Med. Assoc. J. 1981; 125: 999-1002.

10 Ferguson E, Scanlon W. Dietary assessment techniques for preschool children. NZDA Proc. 2000; 5: 80-3.

11 Marshall R. Diet Entry and Storage, Diet Cruncher. A Batch Processing Diet Analysis System for the Macintosh. Dunedin: NutriComp, 1997.

12 New Zealand Institute of Crop and Food Research. FOODfiles. Data Files of the New Zealand Food Composition Database, version 9.0. Palmerston North, New Zealand: New Zealand Institute for Crop and Food Research, 1998.

13 Murphy SP, Beaton GH, Calloway DH. Estimated mineral intakes of toddlers: predicted prevalence of inadequacy in village populations in Egypt, Kenya, and Mexico. Am.J. Clin. Nutr. 1992; 56: 565-72.

14 Carriquiry AL. Assessing the prevalence of nutrient inadequacy. Public Health Nutr. 1999; 2: 23-33.

15 Department of Health. Dietary Reference Values for Food Energy and Nutrients for the United Kingdom. Report on Health and Social Subjects. London: HMSO, 1991.

16 Nusser SM, Carriquiry AL, Dodd KW, Fuller WA. A semiparametric transformation approach to estimating usual daily intake distributions. J. Am. Stat. Assoc. 1996; 91: 1440-9.

17 Singer JI, Bachino JJ, Chabali R. Selected laboratory in pediatric emergency care. Emerg. Med. Clin. North Am. 1986; 4: 377-96.

18 Bathgate M, Alexander D, Mitikulena A, Borman B, Roberts A, Grigg M. The Health of Pacific Islands People. Wellington, New Zealand: Public Health Commission, 1994.

19 Gibson RS. Principles of Nutrition Assessment. New York: Oxford University Press, 1990.

20 Mackerras D. Energy adjustment: the concepts underlying the debate. J. Clin. Epidemiol. 1996; 49: 957-62.

21 Brault-Dubac M, Nadeau M, Dickie J. Iron status of FrenchCanadian children: a three year follow-up study. Hum. Nutr. Appl. Nutr. 1983; 37A: 210-21.

22 Kylberg E, Hofvander Y, Sjölin S. Diets of healthy Swedish children 4-24 months old. Acta Paediatr. 1986; 75: 937-46.

23 Kjaernes U, Botten G, Lande B, Nilsson D. Food intake and patterns of feeding of Norwegian infants. Eur. J. Clin. Nutr. 1988; 42: 249-60.

24 McDowell MA, Briefel RR, Alaimo K, Bischof AM, Caughman CR, Carroll MD, Loria CM, Johnson CL. Energy and macronutrient intakes of persons ages two months and over in the United States: Third National Health and Nutrition Examination Survey, Phase 1, 1988-91. Vital Health Statistics of the Centres for Disease Control and Prevention. National Centre for Health Statistics 1994; 255: 4-24.

25 Piccciano MF, Smiciklas-Wright H, Birch LL, Mitchell DC, Murray-Kolb L, McConahy KL. Nutritional guidance is needed during the dietary transition in early childhood. Pediatrics 2000; 106: 109-14.

26 Fairweather-Tait S, Fox T, Wharf G, Eagles J. The bioavailability of iron in different weaning foods and the enhancing effect of a fruit drink containing ascorbic acid. Pediatr. Res. 1995; 37: 389-94.

27 Hallberg L, Rossander-Hultén L, Brune M, Gleerup A. Calcium and iron absorption: mechanism of action and nutritional importance. Eur. J. Clin. Nutr. 1992; 46: 317-27.

28 Hallberg L. Iron absorption and iron deficiency. Hum. Nutr. Clin. Nutr. 1982; 36: 259-78.

29 Mira M, Alperstein G, Karr M, Rammuthugala G, Causer J, Niec A, Lilburne A-M. Haem iron intake in 12-36 month old children depleted in iron: case-control study. BMJ 1996; 312: $881-3$.

30 Karr M, Alperstein G, Causer J, Mira M, Lammi A, Fett MJ. Iron status and anaemia in preschool children in Sydney. Aus. N.Z. J. Public Health 1996; 20: 618-22.

31 Engelmann MD, Sandström B, Michaelsen KF. Meat intake and iron status in late infancy: an intervention study. $J$. Pediatr. Gastroenterol. Nutr. 1998; 26: 26-33.

32 Engelmann MD, Davidsson L, Sandström B, Walczyk T, Hurrell RF, Michaelsen KF. The influence of meat on nonheme iron absorption in infants. Pediatr. Res. 1998; 43: 768-73.

33 Greene-Finestone L, Feldman W, Luke B. Prevalence and risk factors of iron depletion and iron deficiency anemia among infants in Ottawa-Carleton. J. Cdn. Diet. Assoc. 1991; 52: $20-3$.

34 Nutrition Committee, Canadian Paediatric Society. Meeting the iron needs of infants and young children: an update. Can. Med. Assoc. J. 1991; 144: 1451-4.

35 Male C, Persson LÅ, Freeman V, Guerra A, van’t Hot MA, Haschke $\mathrm{F}$ and the Euro-Growth Iron Study Group. Prevalence of iron deficiency in 12-mo-old infants from 11 European areas and influence of dietary factors on iron status (Euro-Growth study). Acta Paediatr. 2001; 88: 1333-7.

36 Freeman VE, Mulder J, van't Hof MA, Hoey HMV, Gibney MJ. A longitudinal study of the iron status in children at 12, 24 and 36 months. Public Health Nutr. 1998; 1: 93-100.

37 Daly A, MacDonald A, Aukett A, Williams J, Wolf A, Davidson J, Booth IW. Prevention of anaemia in inner city toddlers by an iron supplemented cows' milk formula. Arch. Dis. Child. 1996; 75: 9-16.

38 Fuchs GJ, Farris RP, DeWier M, Hutchinson SW, Warrier R, Doucet H, Suskind RM. Iron status and intake of older infants fed formula vs cow milk with cereal. Am. J. Clin. Nutr. 1993; 58: $343-8$.

39 Gill DG, Vincent S, Segal DS. Follow-on formula in the prevention of iron deficiency: a multicentre study. Acta Paediatr. 1997; 86: 683-9.

40 Morley R, Abbott R, Fairweather-Tait S, MacFadyen U, Stephenson T, Lucas A. Iron fortified follow on formula from 9 to 18 months improves iron status but not development or growth: a randomised trial. Arch. Dis. Child. 1999; 81: $247-52$.

41 Singhal A, Morely R, Abbott R, Fairweather-Tait S, Stephenson T, Lucas A. Clinical safety of iron-fortified formulas. Pediatrics 2000; 105: 1-6.

42 American Academy of Pediatrics Committee on Nutrition. Iron fortification of infant formulas. Pediatrics 1999; 104: $119-23$.

43 Lonnerdal B, Hernell O. Iron, zinc, copper and selenium status of breast-fed infants and infants fed trace element fortified milk-based infant formula. Acta Paediatr. 1994; 83: $367-73$.

44 Lund EK, Wharf SG, Fairweather-Tait S, Johnson IT. Oral ferrous sulfate supplements increase the free radicalgenerating capacity of feces from healthy volunteers. Am. J. Clin. Nutr. 1999; 69: 250-5.

45 Statistics New Zealand. Census 96 with Supermap3 and for GIS and Mapping (Computer). Wellington, New Zealand/ Melbourne, Victoria: Statistics New Zealand, Space-Time Research, 1997. 